\section{Quantity of reinforcement and fixed-interval performance: Within-subject effects}

DONALD MELTZER and JAMES A. $B R A H L E K$, Southern Illinois University, Carbondale, Ill. 62901

Five rats were conditioned to press a lever on a fixed-interval 3-min schedule of food reinforcement. The experimental chamber was light and dark on alternate days. When the chamber was lit, the reinforcement was three 45-mg food pellets. When the chamber was dark, the reinforcement was one 45-mg food pellet. All Ss developed the typical pattern of accelerating response rates during the fixed interval. However, acceleration of rate was faster and terminal rate was higher when the reinforcement consisted of three pellets rather than one pellet. When the data were converted to proportions of total responses in successive interval quartiles, the response distribution was shown to be the same during light and dark sessions.

Meltzer \& Brahlek (1968) recently described the effects of different reinforcement quantities on the fixed-interval (FI) performance of two groups of rats. The Ss in both groups were reinforced on an FI 3-min schedule, but Ss in the first group received a 1-pellet reinforcement while $S s$ in the second group received a 3-pellet reinforcement. Response rates of the two groups were compared in successive quarters of the 3-min interval, and it was found that differences in rate increased as the interval progressed. However, when the mean percent of responses emitted in successive quarters of the FI was calculated, the two groups were shown to have almost identical response distributions. The mean response rate of the 3-pellet group during the last three-quarters of the interval could be approximated by multiplying the mean response rate of the 1-pellet group by 1.6.

The data conflicted with the only other description of the effects of reinforcement quantity on response distribution during FI performance. Stebbins, Mead, \& Martin (1959) reported a study in which rats were used as Ss, and the concentration of the sucrose solution reinforcement varied in blocks of sessions between $5 \%$ and $32 \%$. They found that response rate was directly related to sucrose concentration, but they also reported that the distribution of respones within the interval changed as a function of sucrose concentration. As concentration was increased, a larger proportion of the total responses occurred early in the interval and a smaller percentage occurred late in the interval.

There were several differences between the Stebbins et al (1959) and the Meltzer \& Brahlek (1968) studies, one of which was that all Ss experienced all the different reinforcement magnitudes in the former study while each $S$ experienced only one reinforcement quantity in the latter. This experiment examined the effect of different reinforcement magnitudes on FI performance in a within- $S$ design.

\section{METHOD}

Five male hooded rats bred in our laboratory were the Ss. All the Ss were 90-100 days old at the beginning of the experiment and were on a 22-h food-deprivation schedule. Water was always available except during the experimental session.

The experimental chamber had interior dimensions of $7 \frac{1}{2} \times 12 \times 8$ in. A single response lever was located $1-3 / 16$ in. above the grid floor and $1-1 / 2$ in. from the right side of the box. The food hopper was located midway along the base of the front wall, and $45-\mathrm{mg}$ Noyes pellets were used as reinforcement. A small pilot light was located above the bar. Masking white noise was always present in the room in which the experimental chamber was located. Programming and recording equipment was in an adjacent room.

The experimental chamber was dark during the first session, and Ss were reinforced with one food pellet for every barpress. Beginning with the second session, they were reinforced on an FI 3-min schedule that remained in effect for the rest of the experiment. The experimental chamber was jlluminated by turning on the pilot light during the second session, and the reinforced response produced three pellets. On the following day, the chamber was dark and the reinforced response produced only one food pellet. Light and darkness were presented on alternate days for the rest of the experiment, and the magnitude of reinforcement on those days was three pellets and one pellet, respectively.

Sessions were scheduled daily, and a session was terminated by the first reinforcement following $1 \mathrm{~h}$ of session time. Each $S$ had a total of 50 sessions during the experiment, 25 sessions in which it received 3-pellet reinforcements and 25 sessions in which it received 1-pellet reinforcements. The data from the last 10 sessions-five 3-pellet sessions and five 1 -pellet sessions-were used in the statistical analysis.

\section{RESULTS}

There were no differences in the frequency of reinforcement during the 3 -pellet and 1-pellet sessions. In none of the last 10 sessions did any $S$ fail to collect reinforcement within a few seconds of the time it became available.

Table 1 shows the mean number of responses the $S s$ made in successive quartiles of the 3-pellet FI schedule and the 1-pellet FI schedule during the last 10 sessions. Mean response rate was significantly higher during the 3-pellet sessions than during the 1-pellet sessions $(F=9.28, \mathrm{df}=1 / 4, \mathrm{p}<.05)$. There was also a significant increase in rate over successive quartiles of the FI $(F=42.39$, $\mathrm{df}=3 / 12, \quad \mathrm{p}<.01)$ and a significant interaction between quartiles and magnitude $(F=14.19, \mathrm{df}=3 / 12, \mathrm{p}<.01)$. When the data of individual $S$ s were examined, there were no consistent differences between their mean rates in the first and second quartiles of 1-pellet and 3-pellet FIs. However, all five Ss responded at higher mean rates in the third and four quartiles of the 3-pellet FI than they did during the third and fourth quartiles of the 1-pellet FI. The rates also diverged as the interval progressed for all five Ss; there was always a greater difference between the number of 3-pellet responses and the number of 1-pellet responses an $S$ made in the fourth quartile than between the number of responses in the third quartile. There was always a greater difference between the number of responses in the third quartile than between the number of responses in the second quartile.

Table 1 also shows the data for all five Ss calculated as the mean percentage of total responses in each quartile of the FI. This was accomplished by dividing the

Table 1

Response Rate, Percent Response, and Ratio of 3-Pellet to 1-Pellet Response Rate in Quarters of the Interreinforcement Interval

\begin{tabular}{|c|c|c|c|c|c|}
\hline \multirow{2}{*}{$\begin{array}{l}\text { Interval } \\
\text { Quarter }\end{array}$} & \multicolumn{2}{|c|}{ Rate (Rs/45 Sec) } & \multicolumn{2}{|c|}{$\%$ of Total Response } & \multirow{2}{*}{$\begin{array}{l}\text { Ratio of 3-Pellet } \\
\text { to 1-Pellet Rate }\end{array}$} \\
\hline & 3-Pellets & 1-Pellet & 3-Pellets & 1-Pellet & \\
\hline 1 & 4.32 & 4.16 & 4.4 & 5.5 & 1.0 \\
\hline 2 & 8.08 & 6.62 & 8.0 & 9.7 & 1.2 \\
\hline 3 & 25.64 & 19.62 & 29.8 & 30.6 & 1.3 \\
\hline 4 & 46.74 & 32.74 & 58.4 & 53.7 & 1.4 \\
\hline
\end{tabular}


total number of responses in a quartile during one session by the total number of responses during that session. The quotient then was multiplied by 100 . The proportions for each quartile at each reinforcement magnitude were transformed to arcsines, and an analysis of variance was performed on the results. Since the proportions were calculated for single sessions, and since there was only one reinforcement magnitude in a single session, the sum of both the 3-pellet proportions and the 1-pellet proportions had to equal 1.0. Consequently, reinforcement magnitude had no significant effect. The proportion of responses in successive quartiles did increase significantly $(F=51.06, d f=3 / 12$, $\mathrm{p}<.01$ ) but the Magnitude by Quartile interaction was not significant. In other words, the percent of total responses in successive quartiles was not affected by reinforcement magnitude. The data of all the Ss showed the same effect.

The last column of Table 1 was obtained by dividing the 3-pellet response rate by the 1-pellet response rate at each quarter of the interval. During the last three quarters of the interval, the number of 3-pellet responses could be approximated by. multiplying the number of 1-pellet responses by a factor ranging from 1.2 to 1.4. The size of the multiplier varied for individual Ss, but the phenomenon was basically the same for all Ss.

\section{DISCUSSION}

Response distribution, as measured by percentages, was not affected by reinforcement quantity either when individual $S$ s experienced only one quantity of reinforcement (Meltzer \& Brahlek, 1968) or when they experienced two quantities of reinforcement. Apparently the results reported by Stebbins et al (1959), in which response distribution changed as a function of sucrose concentration, were caused by some factor other than exposure of individual $S s$ to different reinforcers. Either their use of sucrose as a reinforcer or the use of different reinforcers in successive blocks of sessions could have accounted for their results.

The performance generated by FI schedules has not been explained consistently, but one of the theoretical positions that has gained wide acceptance was proposed by Dews (1962). He said that the FI performance could be explained as a delayed reinforcement gradient. There were few responses early in the interval because reinforcement was delivered only after a long delay. Response rate increased as the interval progressed because the delay of reinforcement decreased. Since response-rate differences between the two quantity conditions in this study increased as the interval progressed, it might be inferred that quantity and delay interacted. But response distribution was not affected by reinforcement quantity, and the interaction therefore must be interpreted with care. Acceleration of response rate during the interval was a function of reinforcement quantity; but acceleration of response rate relative to the terminal rate of a $S$ was not related to reinforcement quantity.

Meltzer \& Brahlek (1968) claimed that the response distribution during the interval might be a better index of the delay gradient than response rate. In that case, it could be concluded that the delay gradient was unaffected by quantity of reinforcement. If the gradient is then assumed to reflect some minimum response probability, the divergence in response rate as the interval progressed could be explained by hypothesizing that reinforcement quantity served only to multiply this minimum response probability by some constant factor. The relatively constant ratio of 3-pellet rate to 1-pellet rate during the last three quartiles of the interval provides further support for such a hypothesis.

\section{REFERENCES}

DEWS, P. B. The effect of multiple periods on responding on a fixed-interval schedule. Journal of the Experimental Analysis of Behavior, 1962, 5, 369-374.

MELTZER, D., \& BRAHLEK, J. A. Quantity of reinforcement and fixed interval performance. Psychonomic Science, 1968, 12, 207-208.

STEBBINS, W. C., MEAD, P. B., \& MARTIN, J. $M$. The relation of amount of reinforcement to performance under a fixed-interval schedule. Journal of the Experimental Analysis of Behavior, 1959, 2, 351-355.

\title{
Positive contrast obtained in the Lashley maze under different drive conditions*
}

\author{
MITRI E. SHANAB and HUGH J. FERRELL \\ Fresno State College, Fresno, Calif. 93726
}

Two groups of male albino rats were given one trial a day in a Lashley maze under high deprivation conditions and received either 1 or 22 pellets (Phase 1). This particular maze was used as a control for slowing the Ss' running speed. Following stable performance in Phase 1 , each group was subdivided into a high and low drive condition, and each $S$ received 22 pellets (Phase 2). In Phase 3, all Ss were extinguished under the same drive conditions prevailing in Phase 2. It was found that the large-reward Ss ran significantly faster than the small-reward Ss in Phase 1. Regardless of drive conditions, the Ss that had received small reward in Phase 1 ran significantly faster in both Phases 2 and 3 than those that had received large reward. The results were interpreted in terms of absolute and relative views of reinforcement.

Ss shifted from large to small reward in a runway situation perform at a significantly

* Supported by a faculty research grant awarded to the senior author. lower level than Ss receiving small reward all the time. This phenomenon, viz, the negative contrast effect, is more reliably found in the runway than is its observe, the 